\title{
One plus One is More Than Two? Reaping From the Synergy between Indigenous and Scientific Knowledge to Climate Adaptation in Ghana
}

\author{
Goodlet Owusu Ansah ${ }^{1 *}$, Lawrencia Pokuah Siaw ${ }^{1}$ and Reverend John Manu ${ }^{2}$ \\ ${ }^{1}$ Department of Geography and Rural Development, Kwame Nkrumah University of Science and Technology, Ghana \\ ${ }^{2}$ Ashanti Regional Director, Ministry of Food and Agriculture (MoFA), Ghana
}

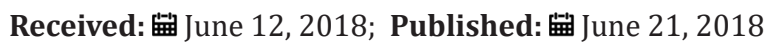

*Corresponding author: Goodlet Owusu Ansah, Department of Geography and Rural Development, Kwame Nkrumah University of Science and Technology, Ghana

\begin{abstract}
The rapid escalation and dangers of global climate change is bourgeoning astronomically and thus places colossal demands on stakeholders to marshal innovative ways and processes for connecting knowledge systems to tackle its negative upshots. These demands in contemporary climate related discourses have led to calls for the integration of indigenous knowledge (IK) and scientific knowledge (SK) sources in climate adaptation efforts. However, studies that advocate and utilize the co-production of IK and SK as the way forward to climate adaptation efforts in Ghana remain scanty. This paper supports by reporting promising outcomes in economies that have embraced the co-production of IK and SK into their adaptation action plans. It is envisaged that this paper will spark stakeholder discussions and subsequently galvanize efforts leading to the integration of both IK and SK into adaptation policies in Ghana. Thus, one plus one can be more than two should Ghana thread on the path of knowledge co-production in climate adaptation initiatives.
\end{abstract}

Keywords: Global climate change; Indigenous knowledge; Scientific knowledge; Climate adaptation

\section{Opinion}

Copious evidence supports climate change-induced decline in crop and livestock productivity in the global landscape [1,2] , more especially in weather-sensitive agricultural production regions such as sub-Saharan Africa where those most vulnerable to these impacts are the indigenous people whose source of livelihood depends solely on small-scale farming. Presently, the agricultural sector contributes $22 \%$ of Ghana's GDP [3] and employs $42 \%$ of the economically active workforce [4]. In 2017, Ghana's GDP recorded a growth rate of $8.5 \%$, with the agriculture sector expanding from a growth rate of 3.0 percent in 2016 to 8.4 percent in 2017 [5]. Nonetheless, the agricultural sector is extremely imperiled as the EPA of Ghana predicts that the country stance to lose about 81.3 square meters of arable land yearly, and yields of maize and other cereal crops will reduce by 7 percent by 2050 . This creates the urgency for best-fit climate adaptation practices to aid adaptation efforts by small-scale farmers, on whom the whole country depends mostly for food supplies. Thus, contemporary adaptation planning necessitates access to the preeminent available knowledge, whatever its source. Unfortunately in Ghana, there exists low levels of awareness and poor understanding of climate change impacts coupled with significant knowledge gaps about climate change processes [6]. These realities have mired effective societal decision making of climate change adaptation and mitigation. There is therefore the need to create such awareness and also integrate indigenous climate change adaptation and mitigation planning with sustainable development and poverty reduction goals [7].

In the light of this, countless developmental projects are known to have been created, funded and accomplished by outside resources and presented into rural communities with the hopes and promises of impacting the lives of small-scale farmers. Assessments indicate that these projects failed to recognize the culture of the people and resulted in low participation and success rates $[8,9]$. 
As a consequence of these letdowns, there was a growing interest in the incorporation of indigenous knowledge (IK) and traditions to increase project participation rate and provide environmentally sound approaches to development. The main reasons for this paradigm shift towards indigenous knowledge and practices were (i) IK stem from the cultural context of the people concerned, (ii) IK evolves in close contact with the specific environment conditions and, (iii) IK is based on intimate knowledge of the environment in the traditional societies Mathias, 1995. Also, according to Adugna [10] and Woodley [11], IK adds value to climate change studies in the following ways; (i) IK systems create a moral economy, (ii) identifies a person within a cultural context, therefore providing decision-making processes or rules of thumb to be followed based on observed indicators or relationships within events, (iii) indigenous knowledge is progressively demonstrating a semblance with scientific methods as many ideas in indigenous knowledge that were once viewed as primitive and misguided, are now seen as appropriate and sophisticated, and (iv) indigenous knowledge systems provide mechanisms for participatory approaches. Valuable local knowledge of relevance to climate change assessment and adaptation is held by rural societies [12]. Thus, these sources see farmers in the agriculture sector as innovators with a sophisticated body of 'indigenous knowledge' comprised of practices gained through experience and transmitted through members of a community $[13,14]$.

Extensive evidence of academic literature that documents how smallholder farmers use knowledge systems to adapt to climatic trends in Africa exist [15-17]. Owusu Ansah [18] in a study that examined indigenous knowledge sources, potency and practices to climate adaptation in the small scale farming sector cited 49 sources to indigenous knowledge in an article for the Journal of Earth Science and Climatic change. Crate [19], referenced 136 sources on climate change and culture in an article for the Annual Review of Anthropology. The United Nations Education, Scientific and Cultural Organization (UNESCO) and the United Nation University (UNU) [20] cited over 300 references in the 2012 report "Weathering Uncertainty: Traditional Knowledge for Climate Change Assessment and Adaptation", which offers a synopsis of key issues and areas of research on indigenous knowledge. UNFCCC [21] ascertained the importance of indigenous knowledge conservation as key to the benefits of an ecosystems-based approach to climate adaptation.

The rapid acceleration and enormity of global environmental change places colossal demands on humanity to marshal innovative ways and processes for connecting knowledge systems that are conducive to sustainability learning and recognize the convolutions of socio-ecological systems and the challenges of the anthropocene $[22,23]$. In recent years, there has been a growing awareness that scientific knowledge (SK) alone is inadequate for solving the climate crisis [24] which has led to growing recognition of local, indigenous, traditional knowledge as an important source of climate knowledge and adaptation strategies. Byg [25] contend that it is erroneous to understand social ecological issues based on SK alone. Thus, the role of indigenous knowledge in climate adaptation in Ghana is required to buttress scientific knowledge adoption [26]. On the other hand, the challenges brought on by global climate change are beyond the lived experience of all knowledge holders, whether scientific or indigenous [27,28]. Owusu Ansah [18] opined that the utilization and efficacies of IK remained indubitable for decades but owing to recent unpredictability in the observed changes in the environment, coupled with the fast increasing susceptibilities of communities to climate change, absolute reliance on the sources of indigenous indicators for correctly predicting environmental changes have become more difficult and obsolete for farmers. Also, the potencies of the identified IK adaptation practices for yielding perfect responses to changes in the environment have become riskier and challenging as time goes by. Even though the relevance of indigenous knowledge sources and practices remain indispensable in the struggle to adapt to climate change, efforts will be more promising should there be a co-production of other knowledge sets (science based) to buttress established positive practices in IK Owusu Ansah [18]. This has led to several calls for interdisciplinary climate change research in modern studies [29-31]. Gratani et al. [32], show that integration of traditional knowledge through scientific validation can be respectful and empowering. To succeed, we cannot afford to lose insights and information originating from multiple knowledge systems [33].

However, studies that advocate and utilize the co-production of multiple knowledge systems that integrate IK and SK as the way forward to climate adaptation efforts in Ghana remain scanty. Aside from the relatively significant physiognomies of spatial locations in climate change manifestations on the global scale, existing literature on the subject is unsatisfactorily scanty in the context of sub-Saharan Africa and Ghana in part [18]. Thus, this paper reviews studies that have presented promising findings from the incorporation of IK and SK elsewhere to inform new approaches to climate adaptation in Ghana. In the face of climate change risks and impacts that remain uncertain and unpredictable, there is a growing need for policies and action that foster the co-production of new knowledge sets, based upon collaborative efforts involving IK and SK holders. Co-management regimes that bring communities and the State together to jointly manage natural resources, have provided an important arena for the development of knowledge coproduction [34-36].

\section{Reaping From the Synergy: One Plus One is More Than Two}

Studies by scholars provide examples from across the globe where the recognition of complementarities across knowledge systems have advanced the understanding, and in many cases improved management, of ecosystems, critical natural resources, and biodiversity. In Africa according to Guthiga and Newsham, (2011) and Kalanda Joshua et al. [37], rainmakers in the Nganyi community of western Kenya and farmers in Nessa Village in 
southern Malawi have worked in partnership with meteorological scientists to create integrated forecasts that are being disseminated by both indigenous and conventional methods to enhance community resilience to climate change and its adversarial upshots. Uganda [38] highlighted the maintenance, protection and continuity of the use of indigenous knowledge in the management of natural resources as a project in its National Adaptation Programmes of Action (NAPA). Also, Ethiopia included the documentation and advancement of indigenous rangeland resource management as a way to enhance resource management practices. Mozambique incorporated the role of local forecasting knowledge in strengthened early warning systems for detecting changes in the environment. The United Republic of Tanzania [39] encouraged the promotion of indigenous knowledge in the agriculture sector.

In Cape Verde, the Ministry of Environment and Agriculture promoted the need to understand traditional knowledge in relation to variations in the water cycle and agro-silvo-pastoral production systems. In 2008, Liberia recognized the necessity to better integrate indigenous and effective coping strategies into its national development policy and planning in order to better respond to the growing incidence and intensity of climatic shocks so that the country will be in a better position to address the situation within the context of its existing sustainable development policy processes. In West Africa, an initiative has been piloted by the Association for Indigenous Women and Peoples of Chad, the Indigenous Peoples of Africa Coordinating Committee and UNESCO, which brought together pastoralist M'bororo weather forecasting knowledge with scientific seasonal and long-term forecasts. This initiative is grounded on a sequence of discussions and exchanges between indigenous and scientific knowledge holders, with the support of indigenous knowledge experts [40]. This initiative occasioned instances where Meteorological services integrated indigenous knowledge, such as phenological data, into their projections to provide users with more broadly based information [41]. In Kenya and Ghana, multiple avenues of culturally appropriate communications are used to ensure that advisories and forecasts are disseminated to farmers and livestock keepers [42]. Also, CARE International's "Joto Afrika: Climate communication for adaptation" provides an example of a platform where SK provides data for IK holders to assess their decision-making on when to plant. By providing the capacity to develop rainfall records from their own community rain gauges, agro pastoralists can take informed decisions on planting dates.

Based on a report by ACIA [43], The Arctic Council's Arctic Climate Impact Assessment is a successful approach to the collaboration of IK with SK that resulted in the incorporation of a broad set of observations from indigenous peoples alongside a regional assessment of the impacts of climate change in the Arctic. This brought together representatives of IK and SK holders on the Artic Council to cooperate and integrate both knowledge sources into a report that produced two chapters on indigenous perspectives and incorporated nine case studies into the final report. Such collaboration led to a robust knowledge base on the impacts of climate change on the Arctic, with indigenous and scientific knowledge supporting each other $[43,44]$.

\section{Conclusion}

Transforming governance of biodiversity and ecosystems toward sustainability will require a rich understanding of the complex interactions of people and nature at different scales, and of the drivers and feedbacks that affects these interactions [45]. The rapid acceleration and enormity of global environmental change places colossal demands on humanity to marshal innovative ways and processes for connecting knowledge systems that are conducive to sustainability learning and recognize the convolutions of socioecological systems. We argue that to achieve this, the science-policy community needs to embrace a diversity of knowledge systems, and when connecting to knowledge from local or indigenous communities, it must think beyond aspects that can easily be fitted into conventional models and frameworks. Also, the partial success of the use of traditional knowledge in coping with climate change leads to the conclusion that a healthy relationship between scientific knowledge and traditional or indigenous knowledge - which both have their limitations - is desirable, especially in developing countries where technology for prediction and modeling is least developed [46]. We therefore suggest that, in the face of climate change risks and impacts that remain uncertain and unpredictable, there is an increasing need for procedures and measures that nurture the coproduction of new knowledge sets, grounded on collaborative energies encompassing community-based knowledge holders and natural and social scientists to tackle the climate change bottlenecks that engulf Ghana [18]. Our study demonstrates that understanding and use of climate adaptation strategies should be overarching in the context of Ghana to incorporate indigenous and scientific knowledge to achieve a counterbalance. Through this, the strengths of both knowledge sources will combine to produce promising returns that could be achieved individually; one plus one is more than two $[47,48]$. Therefore, an understanding established on multiple evidences can afford stronger confidence in conclusions where knowledge and understanding converge across knowledge systems. Our findings accentuate the quintessential requirement for efforts that embrace continuous training and education on climate-smart farming practices, on-hand provision of extension officers and up-to-date meteorological data, constant supply of farm inputs and inculcate partnerships and periodic organization of regional-district-community workshops or forums that bring together IK and SK holders to forge new set of measures and mitigating strategies to adeptly tackle climate-induced challenges on the agriculture sector of Ghana.

\section{References}

1. Deressa T, Hassan RM, Alemu T, Yesuf M, Ringler C (2008) Analyzing the Determinants of Farmers' Choice of Adaptation Methods and Perceptions of Climate Change in the Nile Basin of Ethiopia. Environment and Production Technology Division, Ethiopia. 
2. Lobell DB, Burke MB, Tebaldi C, Mastrandrea MD, Falcon WP, et al. (2008) Prioritizing climate change adaptation needs for food security in 2030. Journal of Science 319(5863): 607-610.

3. World Fact Book (2014) Central Intelligence Agency, Ghana.

4. Ghana Statistical Service (2012) Ghana Living Standards Survey 6, Labour force module 2012-2013.

5. Ghana Statistical Service (2018) Ghana's GDP growth for 2017 hits 8.5 percent.

6. Mensah A, Tweneboah E, Gordon C (2009) Integrating climate change adaptation and mitigation in development planning, Post Dialogue report presented at the National Science-Policy Dialogue in Ghana, October 19-21, 2009, Centre for African Wetlands, University of Ghana, Legon.

7. Macchi M, Oviedo G, Gotheil S, Cross K, Boedhihartono A, et al. (2008) Indigenous and Traditional Peoples and Climate Change. Gland, Switzerland, IUCN.

8. Howes M (1980) The use of indigenous technical knowledge in development. In Brokensha DW, Werner O, Warren DM (Eds.), Indigenous knowledge systems and development. University Press of America, Lanham, USA.

9. Nyong AO, Kanaroglou PS (1999) Domestic water demand in rural semi-arid north-eastern Nigeria: identification of determinants and implications for policy. Environ Plan A 31(12): 2127-2144.

10. Adugna G (1996) The dynamics of knowledge systems versus sustainable development. Indigenous Knowl Dev Monit 4(2): 31-32.

11. Woodley E (1991) Indigenous ecological knowledge systems and development. Agric Human Values 8(1-2): 173-178.

12. Jiri O, Mafongoya P, Chivenge P( 2015) Smallholder Farmer Perceptions on Climate Change and Variability: A Predisposition for their Subsequent Adaptation Strategies. Journal of Earth Science and Climate Change 6(5): 277.

13. Agrawal, Arun (2003) Indigenous Knowledge and the Politics of Classification. International Social Science Journal 54(173): 287-297.

14. Berkes, Fikret (1999) Sacred Ecology: Traditional Ecological Knowledge and Resource Management. Taylor and Francis, Philadelphia and London.

15. Watts, Michael (1983) Silent violence: Food, famine and peasantry in northern Nigeria. Berkeley, CA: University of California Press, Nigeria.

16. Richard, Paul (1986) Coping with hunger: Hazards and experiment in an African rice farming system. London: Allen and Unwin 86(343): 281.

17. Guthiga P, Newsham A (2011) Meteorologist meeting rainmakers: Indigenous knowledge and climate policy processes in Kenya. IDS Bulletin 42(3): 104-109.

18. Owusu Ansah G, Siaw LP (2017) Indigenous Knowledge: Sources, Potency and Practices to Climate Adaptation in the Small-Scale Farming Sector. J Earth Sci Clim Change 8: 431.

19. Crate SA (2011) Climate and culture: anthropology in the era of contemporary climate change. Annual Review of Anthropology 40: 175194.

20. Nakashima D, Galloway M, Thulstrup H, Ramos C, Rubis J (2012) Weathering Uncertainty: Traditional Knowledge for Climate Change Assessment and Adaptation. UNESCO and United Nations University, Paris and Darwin, Australia.

21. UNFCCC (2011) Ecosystem-based approaches to adaptation: compilation of information. Note by the Secretariat.

22. Folke C, A Jansson, J Rockstrom, P Olsson, SR Carpenter, et al. (2011) Reconnecting to the biosphere. AMBIO 40(7): 719-738.

23. Tabara JD, I Chabay (2012) Coupling human information and knowledge systems with social-ecological systems change: Reframing research, education, and policy for sustainability. Environmental Science \& Policy 28: 71-81.

24. Finucane M (2009) Why science alone won't solve the climate crisis: managing the climate risks in the Pacific. Asia Pacific Issues 89: 1-8.

25. Byg A, Salick J (2009) Local perspectives on a global phenomenon: Climate change in Eastern Tibetan villages. Global Environmental Change 19(2): 156-166.

26. Owusu Ansah G, Siaw LP, Eshun G, Frempong F, Gyasi RM (2017) What we have seen and experienced, from where we stand! Spatio-temporal assessment of climate change manifestations in the Ashanti region of Ghana. Climate Change 3(9): 95-116.

27. Huntington HH, S Fox, F Berkes, I Krupnik, A Whiting, et al. (2005) The changing Arctic: Indigenous perspectives. Arctic Climate Impact Assessment (ACIA). Cambridge University Press, Cambridge, UK.

28. Nuttall M, Berkes F, Forbes B, Kofinas G, Vlassova T, et al. (2005) Hunting, herding, fishing and gathering: indigenous peoples and renewable resource use in the Arctic. In ACIA, Arctic Climate Impact Assessment. Cambridge University Press, Cambridge, pp. 649-690.

29. Jacobs J, Frickel S (2009) Interdisciplinarity: a critical assessment. Annu Rev Sociol 35: 43-65.

30. Bjurström A, Polk M (2011) Physical and economic bias in climate change research: a scientometric study of IPCC Third Assessment Report. Clim Change 108(1-2): 1-22.

31. Mooney HA, Duraiappah A, Larigauderie A (2013) Evolution of natural and social science interactions in global change research programs. Proc Natl Acad Sci 110 (Suppl 1): 3665-3672.

32. Gratani M, JR Butler, F Royee, P Valentine, D Burrows, et al. (2011) Is validation of indigenous ecological knowledge a disrespectful process? a case study of traditional fishing poisons and invasive fish management from the wet tropics, Australia. Ecology and Society 16(3): 25.

33. Cornell S, F Berkhout, W Tuinstra, JD Tabara, J Jager, et al. (2013). Opening up knowledge systems for better responses to global environmental change. Environmental Science \& Policy 28: 60-70.

34. Freeman M, Carbyn L (1988) Traditional Management and Renewable Resource Management in Northern Regions. Boreal Institute for Northern Studies, University of Alberta, Edmonton, Canada.

35. Inglis J (1993) Traditional Ecological Knowledge: Concepts and Cases. Canadian Museum of Nature/International Development Research Centre, Ottawa, Canada.

36. Kofinas G (2002) Community contributions to ecological monitoring: Knowledge coproduction in the US-Canada Arctic Borderlands. In I Krupnik and D Jolly (2002) The Earth is Faster Now: Indigenous Observations of Arctic Environmental Change. Fairbanks, Alaska: Arctic Research Consortium of the United States of America pp. 54-91.

37. Kalanda Joshua M, Ngongondo C, Chipeta L, Mpembeka F (2011) Integrating indigenous knowledge with conventional science: enhancing localised climate and weather forecasts in Nessa, Mulanje, Malawi. J Physics and Chemistry of the Earth 36(14-15): 996-1003.

38. Uganda (2007) Uganda National Adaptation Programmes of Action.

39. United Republic of Tanzania (2007) National Adaptation Programme of Action.

40. Indigenous Peoples of Africa Coordinating Committee (2011) National adaptation platform of indigenous peoples, adaptation policy makers and national meteorological authorities.

41. Ziervogel G, Opere A (2010) Integrating Meteorological and Indigenous Knowledge-Based Seasonal Weather Forecasts in the Agricultural Sector. Weather Change Adaptation in Africa learning paper series. International Development Research Centre, Ottawa, Canada. 
42. CARE International (2013) Joto Afrika: Climate communications for adaptation.

43. ACIA (Arctic Climate Impact Assessment) (2005) Arctic Climate Impact Assessment. Cambridge University Press, Cambridge, UK.

44. Thorpe N, Hakongak N, Eyegetok S, Kitikmeot Elders (2001) Thunder on the tundra: Inuit qaujimajatuqangit of the Bathurst caribou. Generation Printing. Tousignant M and Sioui N. 2009. Resilience and Aboriginal Communities. Journal of Aboriginal Health 5(1): 43-61.

45. Tengo M, Brondizio ES, Elmqvist T, Malmer P, Spierenburg M (2014) Connecting Diverse Knowledge Systems for Enhanced Ecosystem
Governance: The Multiple Evidence Base Approach. AMBIO 43(5): 579591.

46. Gyampoh BA, S Amisah, M Idinoba, J Nkem (2009) Using traditional knowledge to cope with climate change in rural Ghana. Unasylva 60(231/232): 70-74.

47. National Adaptation Programme of Action on Climate Change (NAPA) (2007) Cape Verde.

48. Liberia (2008) National Adaptation Programme of Action.

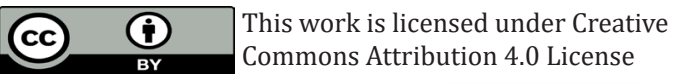

To Submit Your Article Click Here:

Submit Article
DOI: $10.32474 /$ CIACR.2018.03.000158

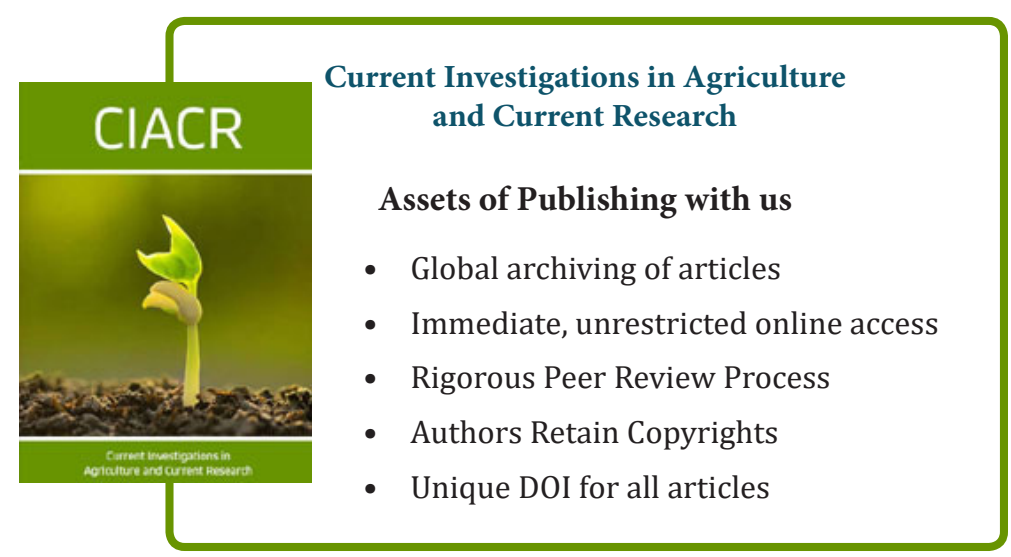

